\title{
A cluster of tuberculosis cases linked to smoking: An under-recognized challenge for tuberculosis elimination
}

\author{
E Rea ${ }^{1,2 *}$, T Leung $^{1}$
}

\begin{abstract}
Background: Smoking is known to increase the risk of tuberculosis (TB) infection, active TB disease, relapse following treatment and death from TB, but its significance is often underappreciated as a potentially reversible risk factor in public health and clinical TB practice in Canada.
\end{abstract}

Objective: To review the current evidence on smoking and the risk of TB, describe a cluster investigation of local TB transmission related to smoking in Toronto, Ontario, and discuss the practical implications of smoking for TB elimination in Canada.

Investigation and public health response: Three TB cases were identified at the same workplace over a two year period. All three strains matched on genotyping. Extensive interviews with the cases and workplace / building managers confirmed that the three cases did not work or socialize together. The only epidemiologic link identified was that all three were regular smokers and used the same location outside the building for smoke breaks. A building ventilation assessment confirmed that unfiltered air was not recirculated between floors. Based on the epidemiological and laboratory evidence, we determined that transmission likely occurred at the partly-sheltered smoking area outside of the worksite. We established and advertised an active case-finding clinic on-site to all workers who frequented smoking areas near the building. Of 60 individuals screened with tuberculin skin testing (TST), no additional active TB cases were identified. One Canadian born person was found to be TST positive. We also offered TB education sessions to all staff in the building, and used the opportunity to promote smoking cessation for interested individuals.

Conclusion: This cluster shows compelling evidence for smoking-related transmission of TB in Toronto. The World Health Organization has called for integration of anti-smoking efforts as a key strategy toward TB elimination. Opportunities to integrate smoking and TB work in Canada include assessment for smoking-related transmission during contact investigations, routine use of smoking cessation supports for contacts and others with latent tuberculosis infection as well as those with active TB, and public health outreach.

\section{Affiliations}

${ }^{1}$ Toronto Public Health, Toronto, ON

${ }^{2}$ Dalla Lana School of Public Health, University of Toronto, Toronto, ON

*Correspondence: Elizabeth. Rea@toronto.ca
Suggested citation: Rea E, Leung T. A cluster of tuberculosis cases linked to smoking: An under-recognized challenge for tuberculosis elimination. Can Commun Dis Rep. 2018;44(3/4):86-90. https://doi.org/10.14745/ ccdr.v44i34a03

\section{Introduction}

Smoking as a risk factor for tuberculosis (TB) has been suspected for a hundred years and well established for several decades (1-3). Smoking interferes with multiple biological mechanisms which are important for defense against both initial infection with TB and subsequent development of active TB disease. These include impaired clearance of secretions in the airways, impaired functioning of pulmonary macrophages and CD4 cells, and decreased production of interferon gamma and Tumor Necrosis Factor-alpha (4-6). Smoking is associated with increased risk of TB infection, of active TB disease, relapse following treatment and death from TB (Table 1). This increased risk has been documented across a wide range of settings and populations, for active and second hand smoke (10-12).
Table 1: Summary of evidence for the increased risk of tuberculosis from smoking

\begin{tabular}{|l|l|}
\hline \multicolumn{1}{|c|}{ Increased risk } & \multicolumn{1}{c|}{ Evidence } \\
\hline TB infection (1) & Pooled odds ratio: 1.83, 95\% Cl, 1.49-2.23 \\
\hline Active TB disease (2) & Relative risk: 2.29, 95\% Cl, 1.93-2.71 a \\
\hline Relapse following treatment (8) & $\begin{array}{l}\text { Adjusted hazard ratio: } 2.04,95 \% \mathrm{Cl} 1.22- \\
3.41^{\mathrm{b}}\end{array}$ \\
\hline Death from TB (9) & Relative risk: 4.5, 95\% Cl 4.0-5.0 \\
\hline
\end{tabular}

Abbreviations: $\mathrm{Cl}$, confidence interval; TB, tuberculosis

a With a dose-response relationship (7)

${ }^{b}$ For those smoking $>10$ cigarettes/day compared to non-smokers 
These modest relative risks-approximately double the risk for non-smokers-can have a major impact on a population scale. The World Health Organization (WHO) estimates that indirectly, smoking causes $20 \%$ of the global TB burden (3): one large study calculated the population attributable risk from smoking is as high as $38 \%$ of all TB cases for men in India (13). Despite this evidence, in our experience smoking status is often not routinely addressed in local TB management activities. While the Canadian Tuberculosis Standards and the national Guidance for Tuberculosis Prevention and Control Programs in Canada both identify smoking as a risk factor for TB, neither include smoking interventions explicitly in their recommendations for clinical care or for programmatic TB prevention work $(14,15)$.

In the general Canadian population, the smoking rate is $18 \%$ (16), but this rate is much higher in some groups that also have higher TB rates, such as homeless populations and many Indigenous communities $(17,18)$. However, smoking can be problematic for those at risk of TB in any population.

Toronto, Ontario has about 300 cases of active TB disease annually. Over $90 \%$ of individuals with TB were born outside Canada, as are half of all Toronto residents $(19,20)$. We describe a cluster of TB transmission related to smoking in Toronto, Ontario and identify the public health program and clinical implications.

\section{Cluster description}

The first case in this cluster was a 34 year old male born in India who developed symptoms about a year after immigration. He was diagnosed with sputum smear 4+ cavitary pulmonary TB in July 2015 and reported smoking heavily. He lived alone. Two workplace contacts were identified but both were lost to follow-up. Over the next two years, two additional TB cases were diagnosed who worked in the same location: a large multi-employer office building with a total of approximately 1,200 workers.

Case \#2 was a 55 year old Canadian born male with no significant history of travel or TB exposure. At diagnosis in December 2016, he was sputum smear 2+ and had an abnormal non-cavitary chest $x$-ray. He reported smoking two packs per week. He worked in the same building as Case \#1 (but on a different floor), did not socialize with others in the building and worked and ate alone.

Case \#3 was a 52 year old male born in India, diagnosed April 2017. He was sputum smear 1+ at diagnosis, had an abnormal non-cavitary chest $x$-ray and reported smoking one pack per week. He worked on the same floor as Case \# 1 but in a different area. Case \#2 and \#3 were not named contacts of each other or of Case \#1.

\section{Genotyping results}

Genotyping by mycobacterial interspersed repetitive units (MIRU)-24 and spoligotyping of all three TB isolates was identical. Whole genome sequencing of sputum samples indicated that Cases \#1 and \#2 had a single nucleotide variance (SNV) difference and Case \#1 and Case \#3 had five SNV differences (i.e., Cases \#2 and \#3 were six SNV differences apart), suggesting Case \#1 was the source case for both Cases \#2 and \#3.

\section{Public health investigation and response}

At the time of investigation, Case \#1 was no longer in the country; however, based on re-interviewing of Cases \#2 and \#3 as well as workplace and building managers, no work or social links could be identified between the three cases other than that they were all regular smokers. All three made frequent use of the same partly-sheltered location near the front entrance of the building for smoke breaks.

A building ventilation assessment confirmed that unfiltered air was not being recirculated between floors; this suggested that transmission via circulating air within the building was unlikely. Based on the epidemiological and laboratory evidence, we determined that transmission likely occurred from Case \#1 to both Cases \#2 and \#3 in the outdoor smoking areas at the worksite.

As transmission had occurred among smokers who were not identified as friends, and no contact list was available to identify those at risk, a site-based approach was used to expand contact follow-up. We established and advertised an active case-finding clinic on-site to all employees in the building (systematic screening for active TB in a pre-determined target group), offering tuberculin skin test (TST) testing and sputum collection to smokers and non-smokers who frequented smoking areas near the building from the time Case \#1 was infectious to the time of the investigation. Of 60 individuals screened, no additional active TB cases were identified. One TST converter was identified and counselled on latent TB infection (LTBI) treatment. We also offered TB education sessions to all staff in the building, and used the opportunity to promote smoking cessation for interested individuals.

\section{Discussion}

This cluster shows compelling evidence for smoking-related transmission in Toronto; these three cases had no other connection, and were not from marginalized communities (though the index case was born in a high-burden country). It is particularly disconcerting that transmission occurred outdoors.

In our experience, smoking is often under-recognized-and smoking interventions under-applied-in public health TB programs as well as clinical TB care.

In practical terms, there are four main strategies for integration of smoking issues in TB work:

- $\quad$ assessing smoking transmission risk as part of contact investigations

- $\quad$ incorporating smoking cessation interventions routinely as an adjunct to prevent active TB among contacts and others with LTBI

- improving clinical outcomes for those with active TB disease

- implementing strategic anti-smoking outreach for high-TB risk populations, in collaboration with substance use prevention programs

The risk of TB transmission is known to be higher in crowded and/or under-ventilated environments (14). The most extreme example of this increased risk of exposure related to smoking is "hot-boxing", where people smoke together in a small confined space (a car or small room) to concentrate marijuana or other smoke in the air and increase the resulting high. Several outbreak investigations have identified smoking marijuana $(21,22)$ and crack cocaine (23) as a risk for transmission.

Although specific populations might be at particularly high risk for smoking-related TB transmission, due to crowding in combination with high smoking rates, our experience in Toronto 
shows it can occur even in a large city with overall lower smoking rates and among non-marginalized individuals. The cluster described in detail above is not the only recent example of smoking-related TB transmission in Toronto. In the last two years we have also documented TB genotype-confirmed transmission related to a shisha (hookah) lounge (one case), tobacco/ marijuana hot-boxing (cluster of six cases, three of whom are also household contacts) and a designated smoking balcony at a homeless shelter (three cases).

Outdoor exposures are generally thought to be very low risk for TB transmission (14). Our case study illustrates that TB transmission can happen even outdoors, particularly in confined spaces with an overhang, the kind of partly-enclosed spaces outside buildings used by many workplace smokers to shelter from the weather. Frequent short exposures during smoke breaks can add up to substantial TB risks for people who smoke regularly together with an infectious individual, even without additional social interaction.

Contact follow-up may be more difficult for such informal smokers groups; there is no registration and participation is often fluid. Smokers may not think of others who are present at informal smoking locations as friends or social contacts. Instead of asking "Who do you smoke with?" it may be more helpful to frame the question as "Who else is there when you are smoking?" Both tobacco and marijuana users may also be reluctant to self-identify or implicate others in an activity that is not always socially accepted (or legal). Site-based screening and creative outreach approaches tailored to the situation may be helpful. The decriminalization (and potential increased use) of marijuana in Canada in 2018 is unlikely to pose a TB risk for most Canadians, but serious consideration should be given to monitor the impact in high-TB burden communities and populations.

People with LTBI who smoke are more likely to benefit from LTBI treatment, because their relative risk for developing active TB is higher than for non-smokers. More explicit attention to this risk factor in routine counselling/clinical care, especially for TB contacts, may help to increase uptake of LTBI treatment. Similarly, smokers with LTBI would also benefit from cessation counselling and referral as a routine part of $L T B I$ care regardless of the decision about LTBI treatment. Individuals with active TB disease who smoke are at risk for worse outcomes, and would also benefit from smoking cessation support.

Strategically, as for populations with high rates of diabetes, TB programs might collaborate with smoking/substance use prevention programs to develop tailored, culturally appropriate smoking prevention and cessation initiatives for local groups with higher TB and smoking rates. These may be Indigenous or homeless communities, but also some immigrant groups. Nationally, the large pool of LTBI-mainly among foreign-born individuals-drives most of the TB in Canada (24). Our cluster also highlights the importance of local by-laws and workplace health and safety related to smoking; many worksites do not permit smoking around building entrances, but we are not aware of specific prohibitions against smoking in partly-enclosed sheltered areas nearby.

Most critically, smoking may be under-recognized in Canada as an escalator of forward TB transmission, particularly in some of the communities most affected by TB outbreaks: homeless populations, northern First Nations reserves and Inuit communities. These are settings where high TB incidence rates, high prevalence of smoking and crowded indoor spaces co-exist and can lead to explosive transmission. The 2012 Aboriginal Peoples Survey found that $52 \%$ of Inuit aged 15 years or older smoked cigarettes daily, almost three times the general Canadian rate (25). The Inuit population also has the highest rate of active TB disease in Canada: $170 / 100,000$ in 2016. This is more than 290 times the rate of active TB disease in Canadian born non-Indigenous people (26). Because the highest risk of active TB disease is in the first two years following infection (14), in situations where smoking is widespread, the higher rate of both TB transmission and progression to active TB disease among smokers can also lead to rapidly evolving clusters of new cases. In this context, integration of TB and tobacco/substance use work across programmatic silos may be helpful. Tuberculosis programs in Nunatsiavut, Newfoundland and in Nunavik, Quebec-both experiencing TB outbreaks-recently developed outreach initiatives incorporating marijuana harm reduction messages, developed in collaboration with community youth (personal communication, T. Buckle and Dr. F. Bouchard, October 4, 2017).

Smoking is one of few potentially reversible risk factors for TB, and affects multiple points in the natural history of the disease. There have been calls from the WHO and others for clinical and program-level integration of anti-smoking and TB elimination work $(3,6)$. We believe there are multiple opportunities to do this in Canada. Interventions to decrease smoking may help to decrease local transmission and reduce the number of new cases in southern cities as well as in the north.

\section{Authors' statement}

ER - Conceptualization, investigation, writing - original draft, writing - review and editing, supervision

$\mathrm{TL}$ - Conceptualization, investigation, writing - original draft, writing - review and editing

Elizabeth Rea was the Guest Editor of this issue of CCDR, but recused herself from taking any editorial decisions on this manuscript. Decisions were taken by the Editor-in-Chief, Dr. Patricia Huston.

\section{Conflict of interest}

None.

\section{Contributors}

Adrian Sebastian - Supervision, investigation

Bernard Lee - Investigation

\section{Acknowledgements}

The authors thank the many people who contributed to the cluster investigation, including the individuals with active TB, building manager $\mathrm{A}$. da Cunha, TB nurses at Toronto Public Health, and the staff of the Public Health Ontario TB Lab.

\section{References}

1. Lin HH, Ezzati M, Murray M. Tobacco smoke, indoor air pollution and tuberculosis: a systematic review and 
meta-analysis. PLoS Med 2007 Jan;4(1):e20. https://doi. org/10.1371/journal.pmed.0040020. PubMed (https://www. ncbi.nlm.nih.gov/entrez/query.fcgi?cmd=Retrieve\&db=PubMe d\&list_uids=17227135\&dopt=Abstract).

2. Bates MN, Khalakdina A, Pai M, Chang L, Lessa F, Smith KR. Risk of tuberculosis from exposure to tobacco smoke: a systematic review and meta-analysis. Arch Intern Med 2007 Feb;167(4):335-42. Epub 2011 Feb 28. http://dx.doi. org/10.1001/archinte.167.4.335

3. World Health Organization. Tuberculosis \& Tobacco Final TB Fact Sheet. World Health Organization; November 2009 [cited 2017 Nov 2]. http://www.who.int/tobacco/resources/ publications/factsheet_tub_tob.pdf

4. Shang S, Ordway D, Henao-Tamayo M, Bai X, Oberley-Deegan $\mathrm{R}$, Shanley $\mathrm{C}$ et al. Cigarette smoke increases susceptibility to tuberculosis-evidence from in vivo and in vitro models. J Infect Dis 2011 May;203(9):1240-8. http://dx.doi. org/10.1093/infdis/jir009. PubMed (https://www.ncbi.nlm. nih.gov/entrez/query.fcgi?cmd=Retrieve\&db=PubMed\&lis t_uids=21357942\&dopt=Abstract).

5. O'Leary SM, Coleman MM, Chew WM, Morrow C, McLaughlin AM, Gleeson LE et al. Cigarette smoking impairs human pulmonary immunity to Mycobacterium tuberculosis. Am J Respir Crit Care Med 2014 Dec;190(12):1430-6. http://dx.doi. org/10.1164/rccm.201407-13850C. PubMed (https://www. ncbi.nlm.nih.gov/entrez/query.fcgi?cmd=Retrieve\&db=PubMe d\&list_uids=25390734\&dopt=Abstract).

6. van Zyl-Smit RN, Brunet L, Pai M, Yew WW. The convergence of the global smoking, COPD, tuberculosis, HIV, and respiratory infection epidemics. Infect Dis Clin North Am 2010 Sep;24(3):693-703. http://dx.doi.org/10.1016/j. idc.2010.04.012. PubMed (https://www.ncbi.nlm.nih. gov/entrez/query.fcgi?cmd=Retrieve\&db=PubMed\&list_ uids $=20674799 \&$ dopt $=$ Abstract).

7. Lin HH, Ezzati M, Chang HY, Murray M. Association between tobacco smoking and active tuberculosis in Taiwan: prospective cohort study. Am J Respir Crit Care Med 2009 Sep;180(5):475-80. http://dx.doi.org/10.1164/ rccm.200904-05490C. PubMed (https://www.ncbi.nlm. nih.gov/entrez/query.fcgi?cmd=Retrieve\&db=PubMed\&lis t_uids=19542475\&dopt=Abstract).

8. Yen YF, Yen MY, Lin YS, Lin YP, Shih HC, Li LH et al. Smoking increases risk of recurrence after successful anti-tuberculosis treatment: a population-based study. Int J Tuberc Lung Dis 2014 Apr;18(4):492-8. http://dx.doi.org/10.5588/ ijtld.13.0694. PubMed (https://www.ncbi.nlm.nih.gov/ entrez/query.fcgi?cmd=Retrieve\&db=PubMed\&list_ uids $=24670708 \&$ dopt=Abstract).

9. Gajalakshmi V, Peto R, Kanaka TS, Jha P. Smoking and mortality from tuberculosis and other diseases in India: retrospective study of 43000 adult male deaths and 35000 controls. Lancet 2003 Aug;362(9383):507-15. http://dx.doi. org/10.1016/S0140-6736(03)14109-8. PubMed (https://www. ncbi.nlm.nih.gov/entrez/query.fcgi?cmd=Retrieve\&db=PubMe d\&list_uids=12932381\&dopt=Abstract).

10. Lindsay RP, Shin SS, Garfein RS, Rusch ML, Novotny TE. The Association between active and passive smoking and latent tuberculosis infection in adults and children in the united states: results from NHANES. PLoS One 2014 Mar;9(3):e93137. https://doi.org/10.1371/journal.pone.0093137.

PubMed (https://www.ncbi.nlm.nih.gov/entrez/query.fcgi?cmd $=$ Retrieve \&db=PubMed\&list_uids=24664240\&dopt=Abstract).
11. Patra J, Bhatia M, Suraweera W, Morris SK, Patra C, Gupta $P C$ et al. Exposure to second-hand smoke and the risk of tuberculosis in children and adults: a systematic review and meta-analysis of 18 observational studies. PLoS Med 2015 Jun;12(6):e1001835. http://dx.doi.org/10.1371/ journal.pmed.1001835. PubMed (https://www.ncbi.nlm. nih.gov/entrez/query.fcgi?cmd=Retrieve $\& d b=$ PubMed\&lis t_uids=26035557\&dopt=Abstract).

12. Huang CC, Tchetgen ET, Becerra MC, Cohen T, Galea J, Calderon $\mathrm{R}$ et al. Cigarette smoking among tuberculosis patients increases risk of transmission to child contacts. Int J Tuberc Lung Dis 2014 Nov; 18(11):1285-91. http://dx.doi. org/10.5588/ijtld.14.0309. PubMed (https://www.ncbi.nlm. nih.gov/entrez/query.fcgi? $\mathrm{cmd}=$ Retrieve $\& \mathrm{db}=$ PubMed\&lis t_uids=25299859\&dopt=Abstract).

13. Jha P, Jacob B, Gajalakshmi V, Gupta PC, Dhingra N, Kumar $R$ et al.; RGI-CGHR Investigators. A nationally representative case-control study of smoking and death in India. N Engl J Med 2008 Mar;358(11):1137-47. http://dx.doi.org/10.1056/ NEJMsa0707719. PubMed (https://www.ncbi.nlm.nih. gov/entrez/query.fcgi?cmd=Retrieve\&db=PubMed\&list_ uids=18272886\&dopt=Abstract).

14. Menzies D, editor. Canadian Tuberculosis Standards, 7th edition 2014. Canadian Thoracic Society, Canadian Lung Association and Public Health Agency of Canada, 2014. https://strauss.ca/OEMAC/wp-content/uploads/2013/11/ Canadian_TB_Standards_7th-edition_English.pdf

15. Pan-Canadian Public Health Network. Guidance for Tuberculosis Prevention and Control Programs in Canada [cited 2018 Jan 24]. http://www.phn-rsp.ca/pubs/gtbpcp-oppctbc/ pdf/Guidance-for-Tuberculosis-Prevention-eng.pdf

16. Statistics Canada. Smokers, by sex, provinces and territories (Percent). Statistics Canada; 2016 [cited 2017 Oct 26]. http://statcan.gc.ca/tables-tableaux/sum-som/l01/cst01/ health74b-eng.htm

17. Toronto SH. The Health of Toronto's Homeless Population. Finding Home: Policy Options for Addressing Homelessness in Canada. Canadian Observatory on Homelessness. 2009 [cited 2017 Dec 29]. http://homelesshub.ca/resource/2 2-health-toronto\%E2\%80\%99s-homeless-population

18. Statistics Canada. Table 577-0008- Aboriginal peoples survey, smoking status, by age group and sex, Inuit population aged 15 years and over, Canada and Inuit Nunangat. CANSIM (database) [cited 2018 Jan 3]. http://www5.statcan.gc.ca/ cansim/a26?lang=eng\&retrLang=eng\&id=5770008\&\&patter n=\&stByVal=1\&p1=1\&p2=31\&tabMode=dataTable\&csid=

19. Toronto Public Health. Communicable Disease Surveillance Reports. 2016 [cited 2018 Jan 25]. https://www.toronto.ca/ community-people/health-wellness-care/health-inspectionsmonitoring/communicable-disease-surveillance-reports/

20. Statistics Canada. 2017. Toronto, CDR [Census division], Ontario and Canada [Country] (Table). Census Profile. 2016 Census. Statistics Canada Catalogue no. 98-316-X2016001. Ottawa. Released October 25, 2017 [cited 2017 Nov 1]. www12.statcan.gc.ca/census-recensement/2016/dp-pd/prof/ index.cfm?Lang $=\mathrm{E}$

21. Oeltmann JE, Oren E, Haddad MB, Lake L, Harrington TA, ljaz K et al. Tuberculosis outbreak in marijuana users, Seattle, Washington, 2004. Emerg Infect Dis 2006 Jul;12(7):1156-9. http://dx.doi.org/10.3201/eid1207.051436. PubMed (https:// 
www.ncbi.nlm.nih.gov/entrez/query.fcgi?cmd=Retrieve $\& \mathrm{db}=\mathrm{Pu}$ bMed\&list_uids=16836841\&dopt=Abstract).

22. Munckhof WJ, Konstantinos A, Wamsley M, Mortlock M, Gilpin C. A cluster of tuberculosis associated with use of a marijuana water pipe. Int J Tuberc Lung Dis 2003 Sep;7(9):860-5.

PubMed (https://www.ncbi.nlm.nih.gov/entrez/query.fcgi?cmd $=$ Retrieve\&db=PubMed\&list_uids=12971670\&dopt=Abstract).

23. Leonhardt KK, Gentile F, Gilbert BP, Aiken M. A cluster of tuberculosis among crack house contacts in San Mateo County, California. Am J Public Health 1994 Nov;84(11):1834-6. http:// dx.doi.org/10.2105/AJPH.84.11.1834. PubMed (https://www. ncbi.nlm.nih.gov/entrez/query.fcgi?cmd=Retrieve\&db=PubMe d\&list_uids=7977929\&dopt=Abstract).

24. Gallant V, Duvvuri V, McGuire M. Tuberculosis in Canada - Summary 2015. Can Commun Dis Rep 2017;43(3/4):77-
82. https://www.canada.ca/en/public-health/ services/reports-publications/canada-communicabl e-disease-report-ccdr/monthly-issue/2017-43/ccdr-volume43-3-4-march-2-2017/ccdr-volume-43-3-4-march-2-2017tuberculosis-1.html

25. Bougie $E$, Kohen D. Smoking prevalence among Inuit in Canada. Health Rep 2017 Feb;28(2):10-4. PubMed (https:// www.ncbi.nlm.nih.gov/pubmed/28198984)

26. Vachon J, Gallant V, Siu W. Tuberculosis in Canada, 2016. Can Commun Dis Rep 2018;44(3/4):75-81. https://www. canada.ca/en/public-health/services/reports-publications/ canada-communicable-disease-report-ccdr/ monthly-issue/2018-44/issue-3-4-march-1-2018/article-1tuberculosis-2016.html 